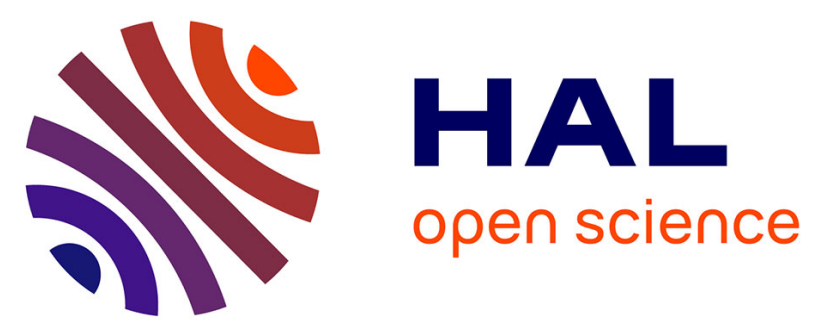

\title{
Product Life-Cycle Assessment in the Realm of Enterprise Modeling
}

Mario Nolte, Monika Kaczmarek-Hess

\section{To cite this version:}

Mario Nolte, Monika Kaczmarek-Hess. Product Life-Cycle Assessment in the Realm of Enterprise Modeling. 10th IFIP Working Conference on The Practice of Enterprise Modeling (PoEM), Nov 2017, Leuven, Belgium. pp.187-202, 10.1007/978-3-319-70241-4_13 . hal-01765271

\section{HAL Id: hal-01765271 \\ https://hal.inria.fr/hal-01765271}

Submitted on 12 Apr 2018

HAL is a multi-disciplinary open access archive for the deposit and dissemination of scientific research documents, whether they are published or not. The documents may come from teaching and research institutions in France or abroad, or from public or private research centers.
L'archive ouverte pluridisciplinaire HAL, est destinée au dépôt et à la diffusion de documents scientifiques de niveau recherche, publiés ou non, émanant des établissements d'enseignement et de recherche français ou étrangers, des laboratoires publics ou privés. 


\title{
Product Life-Cycle Assessment in the Realm of Enterprise Modeling
}

\author{
Mario Nolte and Monika Kaczmarek-Heß \\ University of Duisburg-Essen, Essen, Germany \\ mario.nolte|monika.kaczmarek@uni-due.de
}

\begin{abstract}
Sustainable development' is perceived as a topic of steadily increasing importance. At its core lies a tension between the goals of economic growth and protection of environmental quality. As organizations have a direct impact (e.g., through their production processes) on the sustainability of a society and the planet as a whole, ensuring their sustainable development is crucial. In this paper, we argue that the sustainable development of organizations may be positively influenced by increasing organizations' awareness of environmental impact of their products. Therefore, to support the assessment of environmental impact of product systems, based on ISO 14040, we design a domain-specific modeling method Impact $M$ as part of the Multi-perspective Enterprise Modeling (MEMO) approach. We evaluate it against identified requirements as well as using an exemplary scenario.
\end{abstract}

Key words: Sustainable Development, LCA, MEMO

\section{Introduction}

At the core of sustainable development (SD) lies a tension between the goals of economic growth and protection of environmental quality; and a resulting need to achieve a balance among the environmental, economic, and social aspects [1, 2]. As organizations are part of economy, thus through their choices of, e.g., raw materials, manufacturing process, suppliers, geographic locations; organizations "contribute to the sustainability or unsustainability of a society and the planet as a whole" [1, p. 113]. Indeed, many decisions made by enterprises have causes or consequences that extend beyond the here-and-now of the original question and the decision-maker, and affect the whole supply chain. E.g., a choice between a plastic and a paper bag influences not only material suppliers upstream, but also waste managers downstream, the production chain, or not-direcly involved stakeholders (e.g., fishermen who have to tackle with the plastic waste [3]).

In order to support the SD of organizations, there is a well-recognized need to increase the organization's awareness of the environmental impact of their products $[4,5]$. It thus follows that there is a need to collect and use within the decision processes the relevant information on potential impacts caused by all activities needed to produce a certain product or a type of a product [5, pp. 185-187]. This information should be captured in such a way that would, 
among others, allow to: (1) increase the transparency of the consequences of the decisions made, (2) increase the understanding of possible impact, (3) foster communication between the organizational stakeholders involved in the decision making process, and (4) account for various perspectives on an enterprise and consider them in an integrated manner $[4,6,7]$.

In this paper, we propose to apply conceptual modeling in general, and enterprise modeling in particular, in order to reach the above aims. Enterprise modeling (EM) supports sense-making of an organization and thus, focuses on the construction and application of conceptual models to describe, analyze, and (re-)design different aspects of an enterprise action system and information system $[8,9]$. In opposition to the pure textual form that may be used to collect, aggregate and represent information on the environmental impact of products and services, we argue that conceptual models can be used to express information in a more structured manner which is considered to better support understanding [10] and be more comprehensible to involved actors [11, p. 93].

The main goal of our research is thus to develop a modeling method supporting an assessment of potential environmental impact of enterprises and their products. Since the highest enterprise's impact results from the production and the consumption of products, we focus on the products life-cycle analysis, i.e., on the Life-Cycle Assessment (LCA) method. LCA provides a structured, comprehensive perspective to quantify material and energy flows and their associated emissions in the life-cycle of products (i.e., goods and services from cradle-tograve) so that whole product systems are considered [12, 13].

We follow a design-oriented research strategy [14] and contribute a modeling method Impact $M$ that aims at providing a benefit to organizations by supporting their product life-cycle analysis taking into account the sustainability related aspects. To design the postulated method we follow the approach proposed by [15]. Here, we focus on three main resulting artifacts: identified requirements, abstract syntax of proposed language, and its exemplary application.

The paper is structured as follows. First, the concepts of SD and LCA are discussed. Then, the requirements towards a modeling method are identified and used to discuss the existing approaches. Next, a meta model is presented and evaluated as well as an outlook on future steps is given. The paper concludes with final remarks considering assumptions and limitations of the method proposed.

\section{Sustainable Development and Life-Cycle Assessment}

The term sustainability in the context of environmental aspects can be traced back to 1791 when Hans Carl von Carlowitz used it to argue that the amount of lumbered wood should be in accordance with the rate of growth of the forest [16, pp. 105-106]. The term's current prominence was given by the Brundlandt commission that defined sustainable development as a "development that meets the needs of the present without compromising the ability of future generations to meet their own needs" [17, p. 41]. Although this understanding seems to 


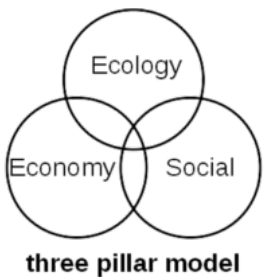

(a) Hierarchical Dimension

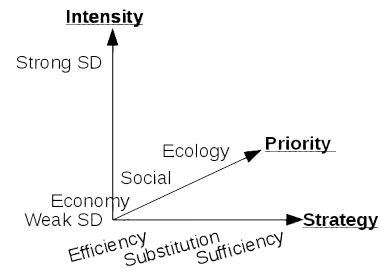

(b) Three Dimensions of SD

Fig. 1: Dimensions of sustainable development

be commonly accepted, it remains unclear how the idea can be conceptualized. Thus, SD is considered to be a contested concept [18]: whereas a distinct discourse can clearly be identified, SD's conceptions, goals and their operationalisations are unclear and juxtaposing [19].

To provide a guiding orientation for situating and evaluating our work in the context of SD we build on three dimensions: hierarchy, intensity and strategy (Fig. 1b), which we also later use to position our work. The 'hierarchical dimension' refers to the aspect already mentioned: that an ecologic system is a precondition for any social system, which in turn itself is a precondition of any economic system. In literature this dimension is represented either as a Priority Model or Three Pillar Model (cf. Fig. 1a). The 'intensity dimension' concerns the substitutability of natural and man-made resources. While the weak sustainability assumes that it is possible to substitute natural resources through man-made resources [20, p. 11], the strong sustainability is more pessimistic about possible substitutions and sets natural resources as a precondition for any human activity. The strong sustainability results in several rules like, e.g., an assimilation rule requiring that "waste emissions rates should equal the natural assimilative capacities of the ecosystem into which the wastes are emitted" [21, p. 2]. Finally, the third dimension refers to 'strategic options' guiding possible actions related to SD. Here the efficiency strategy asking for more efficiency in production processes (e.g., less waste material while keeping the production output) seems to be intuitive at first glance. But since this strategy might result in a rebound effect, where savings for one product may lead to a higher consumption in total [22, 23, pp. 96-100], other options are needed. Beside a substitution strategy where certain products should be substituted by products with the same functionality (e.g., plastic bags through linen bags), a sufficiency strategy is proposed asking for a behavioral change in production and consumption processes that result in a self-limitation of consumers.

Life-Cycle Assessment (LCA) and ISO 14040: LCA is a well established method to collect information about environmental impact of products and services $[12,13]$. With respect to SD it allows at least to satisfy the efficiency strategy by capturing current consumption of raw material [12]. LCA, although having some limitations (e.g., subjectivity and uncertainty regarding interrelationships of ecological causes and effects [25]), is considered to be the 
Table 1: Selected concepts proposed in ISO 14040 for LCA [24, pp. 7-14]

\begin{tabular}{ll}
\hline Term & Definition \\
\hline life cycle & $\begin{array}{l}\text { "consecutive and interlinked stages of a product system, from raw material acquisi- } \\
\text { tion or generation from natural resources to final disposal" [p. 7] }\end{array}$ \\
\hline product & "any goods or service" [p. 8] \\
\hline product & "collection of unit processes with elementary and product flows, performing one or \\
system & more defined functions, and which models the life cycle of a product" [p. 11] \\
\hline sys. boundary & "set of criteria specifying which unit processes are part of a product system" [p. 11] \\
\hline functional unit "quantified performance of a product system for use as a reference unit" [p. 10] \\
\hline unit & "smallest element considered in the life cycle inventory analysis for which input and \\
process & output data are quantified" [p. 12] \\
\hline impact & "class representing environmental issues of concern to which life cycle inventory \\
category & analysis results may be assigned" [p. 13] \\
\hline category & "attribute or aspect of natural environment, human health, or resources, identifying \\
endpoint & an environmental issue giving cause for concern" [p. 12]
\end{tabular}

best available instrument for "evaluating the potential environmental impacts of manufacturing processes or products from cradle-to-grave" [12, p. 223]. An important step to consolidate LCA procedures or methods was the development of international standards ISO 14040 [26] and ISO 14044 [24], which contributed to LCA's acceptance [27] and development of LCA software [28].

The application of LCA is based on several concepts (cf. Table 1), and is guided by four main phases [24]: (1) goal and scope definition, (2) life-cycle inventory analysis, (3) life-cycle impact assessment, and (4) interpretation. Those phases should allow to assess environmental impact in an iterative process, which should be guided by seven main LCA principles defined within ISO 14040 [26, pp. 14-15]. Firstly, a life-cycle perspective (P1) postulates accounting for "the entire life cycle of a product, from raw material extraction and acquisition, through energy and material production and manufacturing, to use and end of life treatment and final disposal" [24]. Secondly, LCA has an environmental focus (P2) (economic and social aspects are outside of its scope). The basis of LCA is a relative approach making use of a functional unit $(\mathbf{P 3})$. The latter quantifies the intended use of certain product systems (e.g., four cups of coffee per day over a period of four years), which allows to normalize assessment data so that different product systems can be compared regarding their impacts (e.g., amount of $\mathrm{CO}_{2}$ produced by a product system of a push-through pot or of a fully automated coffee machine). To contribute to the comprehensiveness and consistency of the analysis, an iterative approach $(\mathbf{P} 4)$ should be followed. To ensure a proper interpretation of results, transparency (P5) in executing LCAs should be ensured. Next, LCA postulates comprehensiveness (P6) and thus, tries to consider all relevant aspects of natural environment, human health and resources, in order to identify potential trade-offs. Finally, LCA promotes priority of scientific approach $(\mathbf{P 7})$, thus, decisions are preferably based on natural science.

\section{Goals and Requirements}

Goals and main scenarios: To support the organizations' SD, as outlined in Sect. 1, the proposed method should allow to collect, document, aggregate 
and present data about potential environmental impacts of products along their entire life-cycle. Because of the contesting interpretations of SD, the method should not provide a solution on its own, but it should allow to collect and document a potential environmental impact within models which can be used in the form of diagrams for discursive decision making.

Exemplary use scenarios that should be supported by the method correspond to the phases proposed by ISO 14040 (cf. Sect. 2). First, the Goal and Scope Definition (Scenario 1) is performed during workshops, where different stakeholders prepare LCA for a product. It is done by setting the goal and scope of LCA and collecting information about all activities which need to be performed inside and outside of the company to produce, use and dispose or recycle the product. Using a model, those activities are assigned to different life cycle steps of the product system. Annotating the activities' accomplishments will allow in the next step to be more specific about potential impacts (e.g., considering the energy mix of a specific country). Furthermore, using the model, the stakeholders document the boundary of the system and assumptions related to certain activities.

In a second step Life-cycle inventory analysis (Scenario 2) detailed information about material flows (e.g., amount of material or energy consumption) is collected, calculated or estimated per activity documented in the first step. While in some cases concrete measurements are available, in others not all information will be directly available or accessible, so that a supporting model should provide concepts that allow to document calculations, estimations, data sources and of course the amount and type of a typical material flow and impact (e.g., $\mathrm{CO}_{2}$ emission, water consumption). To ensure a better traceability and a proper interpretation of the results (cf. P6), it might be necessary to decompose the activities into more detailed ones and to document assumptions taken.

Life-cycle Impact Assessment (Scenario 3): Because some material flows might have impacts that go beyond their emission or consumption, characterization models are developed allowing asserting specific impact categories representing classes of environmental issues of concern (e.g., global warming potential, stratospheric ozone depletion [29]). In such models material flows of chemical substances are related to impact categories by numerical characterization factors. A supporting diagram in this phase allows to visualize such characterization models by relating chemical substance using its characterization factor to the impact category and resulting impacts (e.g., carziogenic impact of ozone depletion). Annotating sources or attributes indicating the acceptance of an impact, helps also in the next step interpret and evaluate the results of LCA.

Finally, Interpretation (Scenario 4) requires support for the assessment and interpretation of the results. Here decision makers have to assess and evaluate all gathered information (e.g., regarding its appropriateness) and to compare it to alternatives (e.g., by using functional units, cf. P3). For this purpose models may be used to (1) present aggregated information about environmental impacts and related data sources, as well as (2) document whether an element of the product system was assessed. Presenting impacts related to a specific locality allows arguing about environmental aspects with local stakeholders. 
Resulting Requirements: To support the goal and the mentioned scenarios, first, the method should allow for the calculation, analysis and documentation of material flows and potential environmental impact of a product along its entire life-cycle (R1). Using the concepts described in Tab. 1 allows to benefit from the existing knowledge and link to the terminology that potential-users are familiar with. Thus, the method should account for the main concepts of ISO 14040 (R2). In addition, as presented in Sect. 2, the concept of strong sustainability requires avoiding the consumption of non-renewable resources and using renewable ones only as much as they grow again. Thus, to allow assertions on the strong or weak sustainability of a product, it should be possible to differentiate between the consumption of renewable and non-renewable resources $(\mathbf{R 3})$.

As in only rare cases own measurements of environmental impact are available, it should be possible to identify information on environmental effects which is not based on own measurements and such information should be accompanied by notes on data sources, calculations and justifications (R4). While the latter information refers to the type level (e.g., average amount of waste water produced), an own measurement can be related to an instance as well. Thus, the modeling method needs to account for both type and instance level information (R5). Furthermore, reuse and calculation of impact data should be supported, thus, the method should provide means for deriving data based on the model or obtaining data from other data sources (R6).

While conceptual models of one specific product system might support an efficiency strategy, the substitution strategy requires to compare impacts of different product systems which provide the same functionality. Thus, the method should allow for comparing different product systems, by relating to the same functional unit (R7). This leads as well to the need to set a boundary for LCA, therefore the method must allow to justify and document deliberately excluded information on environmental impacts (R8). To assess the local impact of a product system, the method should allow to assign environmental impacts to local areas (R9). Because most environmental impacts might be based on estimations and historical data, the method needs concepts which allow to evaluate the appropriateness of data used (R10), e.g., locality and time of referred data used for calculations. Finally, because the knowledge on environmental impacts is increasing or changing, the method should be open to new findings on causeeffect relationships (R11).

Fullfilment of the requirements by existing EM approaches: A number of modeling languages and methods to model an enterprise and its architecture exist. Examples encompass ArchiMate [30], Architecture of Integrated Information Systems (ARIS) [31], 4EM [9] and Multi-Perspective Enterprise Modeling (MEMO) [8]. These methods are based on different modeling foundations and assumptions, and define different sets of modeling concepts for describing selected facets of organizations. Although all of them, on a high level, support a structured description of enterprises, those approaches are quite different as they have been developed with different purposes and goals in mind [32]. 
To answer a question whether the existing EM approaches fulfill the identified requirements, we consider two aspects: (1) the scope of information required and (2) required expressiveness of the language architecture. Regarding the former, as LCA, to our best knowledge, has not been defined as one of the scenarios to be supported by any of EM approaches [32], it is not surprising that they do not account for the main concepts required for the LCA analysis (except for Product). Therefore, to reach the defined goals and benefit in the analysis from the concepts allowing to describe the enterprise action system and information system, it is necessary to extend an already existing EM method with relevant concepts. To select the candidate for extensions, the requirements regarding the expressiveness need to be considered.

Based on the requirements, an approach is needed that would, among others: (1) support definition of semantically rich concepts, i.e., account for attributes, both on the type and instance level, (2) distinguish between different types of attributes (derived, obtained), and (3) provide a rudimentary support for calculations and analysis. Most of the existing approaches however, on purpose, provide a rather generic set of concepts, without attributes (e.g., ArchiMate), and mostly on the type level, thus, representing the information required is not straightforward possible. The exception is MEMO, whose language architecture not only supports definition of semantically rich concepts, but also allows for differentiating instance and type levels, which allows to consider measured data of a specific product in instance level diagrams, while estimated and calculated data can be assigned to the type level [8]. Although the support for calculations as such is not provided, we chose MEMO as point of departure for our work.

\section{ImpactM: Abstract Syntax}

Modeling Guidelines Followed: MEMO includes an extensible set of modeling languages, which are defined within a multi-layer language architecture [8] and specified using the MEMO Meta Modeling Language (MML [33]). This architecture adheres to the meta modeling paradigm [8], thus, the abstract syntax of the modeling language is defined in the form of a meta model $\left(\mathrm{M}_{2}\right)$ containing definitions of meta classes, their attributes and relations (i.e., language specification). A meta model is instantiated to create models at the type level $\left(\mathrm{M}_{1}\right)$ (i.e., language application). MML, when compared to other meta modeling languages provides additional language constructs allowing to express, e.g., intrinsic attributes and relations (instantiated only on the instance level and not on the type level), obtainable and derivable attributes (attributes which can be derived from other attributes within the same model or are obtainable from external sources), or language level types (instantiated on the type level, but no further, visualized with a grey background of the concept's name) [33].

Defining a meta model requires making a number of decisions, among others, (1) whether a concept should become part of a language at all, (2) whether a concept should be part of language specification (i.e., be a meta type, $\mathrm{M}_{2}$ level) or part of language application (i.e., a type, $\mathrm{M}_{1}$ level), and (3) which attributes 
of which types as well as which relations with which cardinalities should be defined. To support decision-making process and ensure the desired quality of the developed meta model, the guidelines proposed in [34] have been applied.

Design Decisions and Main Concepts: The meta model of the proposed language is shown in Fig. 2. Apart from the specification of concepts, it shows exemplary constraints defined using the Object Constraint Language (OCL) [35].

We used the discussed scenarios to identify relevant attributes and relations of rather generic ISO 14040 concepts. In this context, a design decision needed to be made regarding the language level applicable to the identified attributes. While in most cases users might model a typical product system by using average values, it seems also desirable to use single measurements to improve the quality of resulting LCA (cf. R5). Thus, we decided to assign concepts related to average data (e.g., calculations and related data sources) to the type level, and to introduce within meta classes intrinsic attributes which allow to capture concrete instances of a product system and related measurements. This instance data can be used on the type level to derive average values. The average values may be also obtained from external data sources (cf. R6).

This allows, e.g., to gather data on a certain ProductSystem with a specific SerialNumber in the intrinsic attribute measuredAmount of SubstanceAmount. An average value can be derived based on the instance-level data and represented within the relevant type-level concept as avgAmount. This average amount needs to be qualified through a name and unit, which are modeled by using the concept SubstanceFlow, which can also be amended with additional chemical information. Since avgAmount might be also based on a Calculation, which itself might refer to data sources like Literature and be based on an Assumption, we provide concepts allowing to trace and evaluate the appropriateness of calculations (cf. R10). These concepts are defined as language level types since the information they capture refers to a typical substance flow of a product system.

To enable a more differentiated analysis, we introduce a dedicated concept for Transportation with a set of attributes providing information relevant for environmental impacts. In addition, accounting for this concept allows language users to model different variations (e.g., means of transportation, cf. R7) or gather instance information (e.g., concrete fuelConsumption).

From a systematic perspective, it might be argued that the Unit Process is a subsystem of the product system what would enable the use of the composite pattern [36, p. 239] for reusing attributes and relations. Even if this would allow for complex models with nested subsystems, we decided to avoid such complexity with respect to the principle of transparency (cf. P7). In line with ISO 14040 (cf. R2), a ProductSystem can have several UnitProcesses and Transportations which are both related via the LifeCycleStep (e.g., use phase), which itself can indicate that it isExcluded in LCA, but then also needs a justification (cf. constraint $\mathrm{C} 03 ; \mathrm{R} 8$ ). In the context of multiperspective EM, each transportation or unit process can be related using an AnyProcess (defined in OrgML [37]) to existing business process models [37]. In opposition to business processes, each UnitProcess or Transportation includes at least one 
Product Life-Cycle Assessment in the Realm of EM

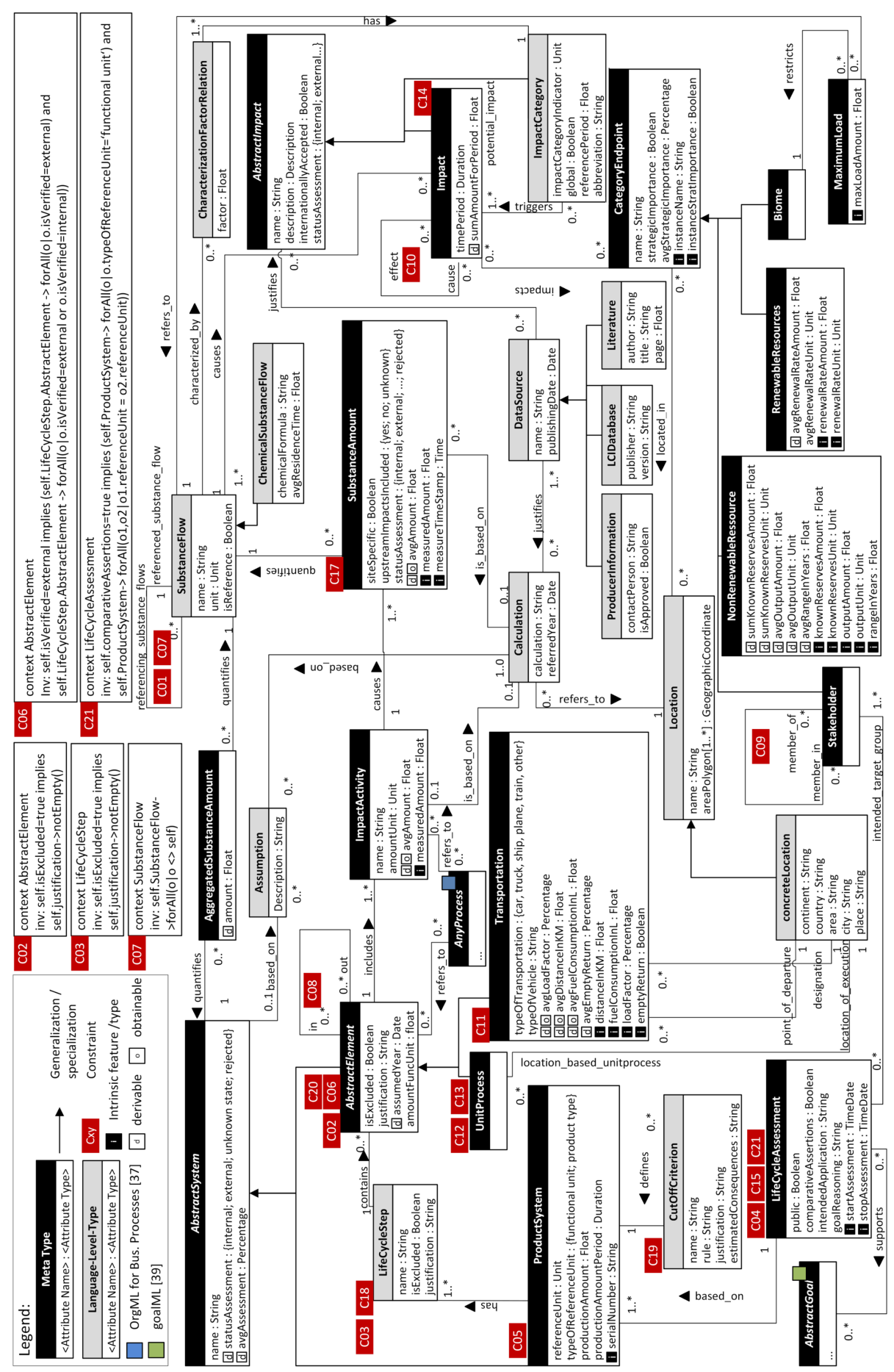

Fig. 2: A Meta Model of ImpactM 
ImpactActivity, which allows to model single activities that cause at least one SubstanceFlow, e.g., like the emission of $1 \mathrm{~kg}$ Halon 1301 (cf. R1). All amounts that are gathered as avgAmount and belong to the same SubstanceFlow can be aggregated by using the AggregatedSubstanceAmount, which can be used to quantify each ProductSystem, UnitProcess or Transportation (cf. R1). Each SubstanceFlow can directly cause an impact (like cancer in the case of Halon 1301) or contribute to an ImpactCategory (like ozone depletion potential in the case of Halon 1301). To argue about this indirect contribution, the meta model offers the possibility to include Literature, which, e.g., might provide the CharacterizationFactor that quantifies the relation between a substance and an ImpactCategory (12, for Halon and ozone depletion [38, p. 259]).

Each Impact might directly, and each ImpactCategory indirectly, impact a category endpoint proposed by ISO 14040 . As this concept described by the standard is still comprehensive, we propose different kinds of CategoryEndpoints, which all can have several instances that might be of StrategicImportance for an enterprise (e.g., a specific lake supplying water for a brewery). While the differentiation between RenewableResource and NonRenewableRessource allows to identify consumption of both kind of resources at first glance (cf. R3), the meta model as proposed here will need further conceptualizations of how to relate different types and instances of an Impact to CategoryEndpoints so that sound assertions regarding strong or weak sustainability of a product system can be substantiated. Finally, in order to provide location relevant information on the type-level diagrams, we defined Location as a language level type.

\section{Evaluation}

In this section, we first position our proposed method in the context of SD using the introduced dimensions (cf. Sect. 2), then show its applicability based on an exemplary scenario, and finally, evaluate it against the requirements which allows us to describe future work needed.

Positioning ImpactM: With respect to the 'priority dimension', due to selecting ISO 14040 as a foundation for our work, the method supports ecological aspects only. Regarding the 'intensity dimension', the method might support both a weak and strong SD, however additional work is required to allow

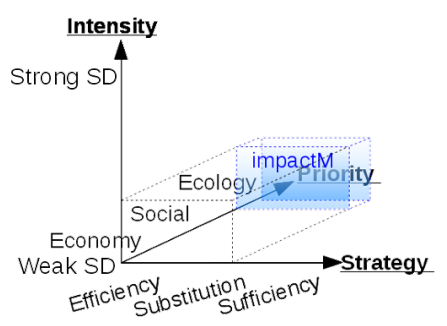

Fig. 3: ImpactM located in the possible dimension of SD 
for addressing the assimilation rule. Therefore, we mark this dimension with a decreasing color gradient (Fig. 3). While an efficiency strategy can clearly be supported in the 'strategy dimension' through documenting current consumptions to assess the efficiency of used substances, a substitution strategy might be supported by the use of the functional unit. A sufficiency strategy however, can only be supported indirectly by providing information about a possible impact that might be used to change behavior of different stakeholders like customers.

Exemplary Application: The application builds on the scenarios as described in the third section. A hotel manager is interested in comparing the environmental impacts of two laundry detergents for internal purposes. For the purpose of a better traceability, the accomplishment of LCA is set as a goal and mandated to the Corporate Social Responsibility department (CSR; e.g., by instantiating an EngagementGoal of MEMO GoalML [39], which related to a LifeCycleAssessment and is assigned to the UnitofWork CSR department). To set the goal and the scope of LCA, CSR instantiates the meta class LifeCycleAssessment by providing among others values for the intendedApplication and the goalReasoning. Because the environmental impacts of two detergents should be compared, comparativeAsserstions is set to true, which enforces to set a referenceUnit (C21) while instantiating a ProductSystem (e.g., $1000 \mathrm{~kg}$ clean linen over one year). To learn about as many impacts as possible, CSR decides to gather data about the production, use and disposal of the detergents so that corresponding LifeCycleSteps are instantiated. In the production phase, UnitProcesses like production of packaging or production of surfactants, mixing all ingredients and the Transportation delivery to the laundry, are considered as relevant activities. Internal unit processes and transportation can be referred to existing business process models by using the meta type AnyProcess. Because the waste water treatment in the use phase is the same for both detergents and cannot be influenced, this Unit Process is marked as isExcluded by providing a corresponding justification. Now for each UnitProcess or Transportation data of related ImpactActivities with their SubstanceFlows is gathered. Fig. 4 shows a diagram where impact relevant data is gathered for the UnitProcess of production of packaging. Please note that the concrete syntax as suggested by the legend is only preliminary.

Beside gathering and documenting all data and calculations for each unit process, the diagram type proposed here allows to answer analytical questions,

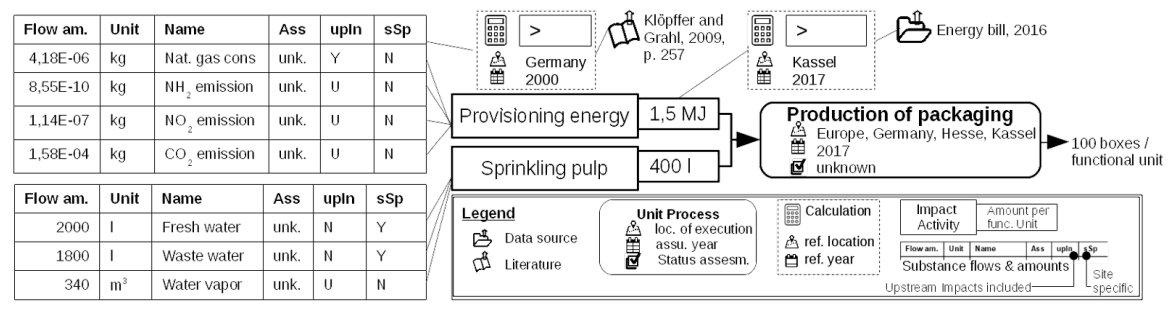

Fig. 4: An exemplary diagram to support inventory analysis 


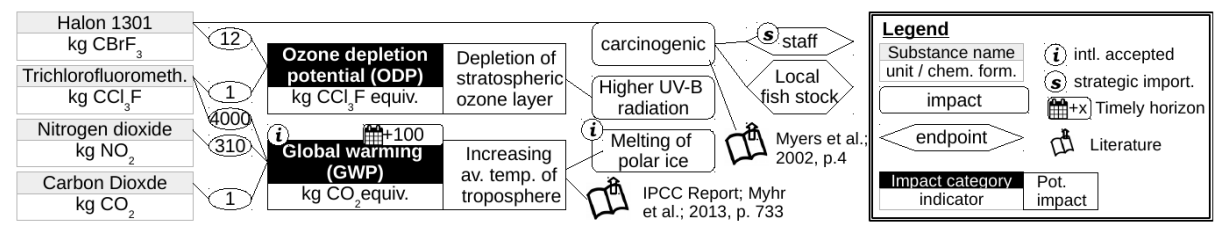

Fig. 5: An exemplary diagram to support impact assessment

which concern appropriateness of the data (e.g., suitable time and locality, data sources used) by assessing calculations or comparing the location of execution of a unit process and data used for the calculation. Furthermore, the status of the assessment can be set by using the attribute statusAssessment.

After documenting the first activities with the corresponding Subst anceFlows, CSR is using different data sources to determine potential impacts of substance flows on different kinds of Endpoints. The diagram as shown in Fig. 5 allows the modeler to relate a direct Impact, or to depict other environmental issues of concern by relating an ImpactCategory over a CharacterizationFactorRelation to a SubstanceFlow. It provides an overview about the different kinds of impacts caused by the substances used in a product system, the strength of contribution of a specific substance to an impact, and used literature to trace assertions which are represented in the diagram.

Fulfillment of Requirements and Future Work: The result of the evaluation of the proposed method using the requirements presented in Sect. 3 may be found in Tab. 2. As indicated not all of the requirements are fulfilled to the satisfactory extent. Taking that into account, aside of developing a concrete syntax, two main streams of our future work may be distinguished. The first one relates to the scope of information captured (cf. R2, R3, R9). Namely, there are few concepts, like, e.g., endpoint or resource which require more structured conceptualization. Here representations used in existing LCA software [28] might provide a good starting point. In addition, social aspects could be integrated to the life-cycle perspective built into ImpactM (cf., TracyML, [40]).

The second stream relates to the language architecture followed (cf. R5). Here, the application of MEMO MML allowed to take advantage of the intrinsic features and relations, and thus, to refer to the instance level. However, we faced a challenge connected with, on the one hand, the type differentiation pertaining to the restrictions given by the type/instance dichotomy and the semantic differences between instantiation and specialization, cf. [41], and on the other hand, a need to support a number of different calculations, preferably by different model elements. Therefore, considering the limitations imposed by the language architecture which is based on a fixed amount of levels and based on the semantics of dominant object-oriented programming, as a next step we undertake an attempt to apply a multilevel modeling language like, e.g., FMML ${ }^{\mathrm{x}}$ with an integrated programming and modeling environment [41]. Changing the language architecture should also allow for an integration of the proposed method with existing LCA software tools and relevant databases. 
Table 2: Fulfillment of requirements

\begin{tabular}{|c|c|c|}
\hline$\overline{\mathbf{R}}$ & & \\
\hline$\overline{\mathrm{R} 1}$ & O & $\begin{array}{l}\text { Offering the language user meta classes which provide attributes for calculating, document- } \\
\text { ing and presenting different material flows and related environmental impacts throughout } \\
\text { different life cycle steps allows him analyzing a product for impacts along its life cycle. }\end{array}$ \\
\hline $\mathrm{R} 2$ & (1) & $\begin{array}{l}\text { Choosing ISO } 14040 \text { allowed to build on many terms of the standard and to refine them } \\
\text { for purpose of conceptual modeling. Beside additional concepts that were derived from } \\
\text { our design decisions other concepts of the standard were integrated or refined, e.g., an } \\
\text { intermediate product is built in the method proposed as SubstanceFlow. Because concepts } \\
\text { like allocation and related operations are not considered, further work is needed. }\end{array}$ \\
\hline$\overline{\mathrm{R} 3}$ & (1) & $\begin{array}{l}\text { Associating SubstanceFlow with its related amounts to res } \\
\text { on instance level allows for limited assertions regarding } \\
\text { calculation procedures on type level are not specified, a }\end{array}$ \\
\hline$\overline{\mathrm{R}} 4$ & O & $\begin{array}{l}\text { nted and transparent calculations of en- } \\
\text { traceable way. }\end{array}$ \\
\hline$\overline{\mathrm{R} 5}$ & (1) & $\begin{array}{l}\text { The MEMO language architecture allowed assigning concepts and attributes to type and } \\
\text { instance levels. Considerations for some concepts indicate however that another language } \\
\text { architecture might be more appropriate (e.g., refining a product like discussed in [ } 41 \text {, } \\
\text { p. 321]). }\end{array}$ \\
\hline R6 & 0 & The MEMO MML allows to indicate that data is derived or obtained from other sources. \\
\hline R7 & ○ & $\begin{array}{l}\text { Setting the attribute co } \\
\text { LCA. This requires a } \\
\text { functional unit and ch }\end{array}$ \\
\hline$\overline{\mathrm{R} 8}$ & - & $\begin{array}{l}\text { Using the attribute isExcluded in several meta classes allow modelers to indicate that in- } \\
\text { formation was excluded on purpose. Constraints (e.g., C02) enforce the modeler to provide } \\
\text { a justification in those cases. }\end{array}$ \\
\hline$\overline{\mathrm{R} 9}$ & (1) & $\begin{array}{l}\text { Each Impact can be assigned to a CategoryEndpoint which itself can be assigned to a } \\
\text { Location. The design decisions here indicate however, that other conceptions might be } \\
\text { needed to relate impacts to local areas. }\end{array}$ \\
\hline$\overline{\mathrm{R} 10}$ & 0 & $\begin{array}{l}\text { Setting the attribute statusAssessment allows a user to indicate the evaluation and appro- } \\
\text { priateness of data used. }\end{array}$ \\
\hline$\overline{\mathrm{R} 11}$ & $C$ & ses \\
\hline
\end{tabular}

\section{Conclusions}

In this paper we have shown how conceptual modeling in general, and enterprise modeling in particular, can be used to support the organizations' SD by collecting and presenting information about potential environmental impacts of product systems along their life-cycle. While the exemplary application of ImpactM in the last section indicated the general usage of such a method, the evaluation revealed the need for further work encompassing (1) refinement of concepts and (2) investigating the potentials of multilevel modeling. Furthermore, the positioning of ImpactM within the selected dimensions of SD (cf., Fig. 3) indicated that further work is needed to fully address them.

Beside that, following Hovorka et al. [42], further limitations need to be accounted for, which are connected with conducting research in the area of environmental sustainability. Those limitations are, e.g., boundary issues or uncertainty regarding ecological causes and effects which are, on the one hand, inherent to LCA itself [25], and on the other, result out of the vagueness of the SD topic, which might lead to opportunistic self-representations in the name of transparency while generating opacity $[43,44]$. Especially the last point raises questions how conceptual modeling can be used to improve the transparency of organizations and it is to be covered by our future work as well. 


\section{References}

1. Diesendorf, M.: Models of sustainability and sustainable development. IJARGE 1(2) (2001) 109-123

2. Jabareen, Y.: A new conceptual framework for sustainable development. Environment, Development and Sustainability 10(2) (2008) 179-192

3. Eriksen, M., Lebreton, L.C.M., Carson, H.S., Thiel, M., Moore, C.J., Borerro, J.C., Galgani, F., Ryan, P.G., Reisser, J.: Plastic pollution in the world's oceans: More than 5 trillion plastic pieces weighing over 250,000 tons afloat at sea. PloS one 9(12) (2014) e111913

4. Giddings, B., Hopwood, B., Brien, G.O.: Environment, Economy and Society: Fitting them together into Sustainable Development. Sustainable Development 196 (2002) 187-196

5. Melde, T.: Nachhaltige Entwicklung durch Semantik, Governance und Management. Springer, Wiesbaden (2012)

6. Melville, N.: Information systems innovation for environmental sustainability. MIS Quarterly 34(1) (2010) 1-21

7. Bass, S., Prescott-Allen, R., Carew-Reid, J., Dalal-Clayton, B.: Strategies for National Sustainable Development. Earthscan Publications Limited, London (2013)

8. Frank, U.: Multi-perspective enterprise modeling: Foundational concepts, prospects and future research challenges. SoSyM 13(3) (2014) 941-962

9. Sandkuhl, K., Stirna, J., Persson, A., Wißotzki, M.: Enterprise Modeling: Tackling Business Challenges with the 4EM Method. Springer, Berlin (2014)

10. Thalheim, B.: The science and art of conceptual modelling. In Hameurlain, A., Küng, J., Wagner, R., Liddle, S.W., Schewe, K.D., Zhou, X., eds.: Transactions on Large-Scale Data- and Knowledge-Centered Systems VI. Volume 7600 of LNCS. Springer, Berlin (2012) 76-105

11. Wolff, F.: Ökonomie multiperspektivischer Unternehmensmodellierung. Gabler, Wiesbaden (2008)

12. Chang, Y.J., Neugebauer, S., Lehmann, A., Scheumann, R., Finkbeiner, M.: Life cycle sustainability assessment approaches for manufacturing. In Stark, R., Seliger, G., Bonvoisin, J., eds.: Sustainable Manufacturing: Challenges, Solutions and Implementation Perspectives. Springer, Cham (2017) 221-237

13. Finkbeiner, M.: The International Standards as the Constitution of Life Cycle Assessment: The ISO 14040 Series and its Offspring. In Klöpffer, W., ed.: Background and Future Prospects in Life Cycle Assessment. Springer, Dordrecht (2014) 85-106

14. Österle, H., Becker, J., Frank, U., et al.: Memorandum on design-oriented information systems research. EJIS 20 (2011) 7-10

15. Frank, U.: Outline of a Method for Designing Domain-Specific Modelling Languages. ICB Research Report 42, University of Duisburg-Essen, Essen (2010)

16. Von Carlowitz, H.C., von Rohr, J.B.: Sylvicultura oeconomica, Leipzig (1732)

17. Brundtland Comission: Our common future. Technical report, Oxford University Press, Oxford (1987)

18. Jacobs, M.: Sustainable Development as a Contested Concept. In Dob, A., ed.: Fairness and Futurity: Essays on Environmental Sustainability and Social Justice. Oxford University Press, Oxford (1999) 21-45

19. Gallie, W.B.: Essentially Contested Concepts. In: Meeting of the Aristotelian Society. Volume 56., London, The Aristotelian Society (1956) 167-198

20. Solow, R.M.: The economics of resources or the resources of economics. In Gopalakrishnan, C., ed.: Classic Papers in Natural Resource Economics. Palgrave Macmillan UK, London (1974) 257-276 
21. Daly, H.E.: Toward some operational principles of sustainable development. Ecological Economics 2 (1990) 1-6

22. Grunwald, A.: Nachhaltigkeit. 2. edn. Campus Verlag, Frankfurt (2012)

23. Otto, S., Kaiser, F.G., Arnold, O.: The Critical Challenge of Climate Change for Psychology. European Psychologist 19(2) (2014) 96-106

24. ISO: DIN EN ISO 14044 - Umweltmanagement - Ökobilanz - Anforderungen und Anleitungen (2006)

25. Adensam, H., Ganglberger, E., Gupfinger, H., Wenisch, A.: Wieviel Umwelt braucht ein Produkt? Österreichisches Ökologie Institut, Wien (2000)

26. ISO: DIN EN ISO 14040 - Umweltmanagement - Ökobilanz - Grundsätze und Rahmenbedingungen (2009)

27. Finkbeiner, M., Inaba, A., Tan, R., Christiansen, K., Klüppel, H.J.: The New International Standards for Life Cycle Assessment: ISO 14040 and ISO 14044. The International Journal of Life Cycle Assessment 11(2) (2006) 80-85

28. Seto, K.E., Panesar, D.K., Churchill, C.J.: Criteria for the evaluation of life cycle assessment software packages and life cycle inventory data with application to concrete. Int. Journal of Life Cycle Assessment 22(5) (2017) 694-706

29. Stranddorf, H.K., Hoffmann, L., Schmidt, A.: LCA technical report: impact categories, normalization and weighting in LCA. Update on selec. EDIP97-data (2005)

30. The Open Group: ArchiMate 2.1 Specification: Open Group Standard. The Open Group Series. Van Haren, Zaltbommel (2013)

31. Scheer, A.W.: ARIS - Modellierungsmethoden, Metamodelle, Anwendungen. 4 edn. Springer, Heidelberg (2001)

32. Bock, A., Kaczmarek, M., Overbeek, S., Heß, M.: A comparative analysis of selected enterprise modelling approaches. In Frank, U., et al., eds.: Proc. of PoEM 2014, Berlin, Springer (2014) 148-163

33. Frank, U.: The MEMO Meta Modelling Language (MML) and Language Architecture. 2nd Ed. ICB Research Report 43, University of Duisburg-Essen, Essen (2011)

34. Frank, U.: Some guidelines for the conception of domain-specific modelling languages. In Nüttgens, M., Thomas, O., Weber, B., eds.: Proc. of EMISA 4th Int. Workshop. Volume 190 of LNI., Bonn, German Informatics Society (2011) 93-106

35. Warmer, J.B.: The object constraint language: getting your models ready for MDA. 2. edn. Addison-Wesley, Boston (2003)

36. Gamma, E., Helm, R., Johnson, R., Vlissides, J.: Entwurfsmuster. Addison-Wesley, München (2011)

37. Frank, U.: MEMO Organisation Modelling Language (2): Focus on Business Processes. ICB Research Report 49, University of Duisburg-Essen (2011)

38. Klöpffer, W., Grahl, B.: Ökobilanz (LCA). Wiley-VCH, Weinheim (2009)

39. Overbeek, S., Frank, U., Köhling, C.: A language for multi-perspective goal modelling: challenges, requirements and solutions. CSI 38 (2015) 1-16

40. Fritsch, A., Betz, S.: TracyML Specification. Working Paper 1.0, Karlsruhe Institute of Technology, Karlsruhe (2016)

41. Frank, U.: Multilevel Modeling. BISE 6(6) (2014) 319-337

42. Hovorka, D.S., Labajo, E., Auerbach, N.: Information systems in environmental sustainability: Of cannibals and forks. In vom Brocke, J., Seidel, S., Recker, J., eds.: Green Business Process Management. Springer, Berlin (2012) 59-72

43. Gray, R., Milne, M.: Sustainability reporting: who's kidding whom? Chartered Accountants Journal of New Zealand 81(6) (2002) 66-70

44. Christensen, L.T., Cheney, G.: Peering into transparency: Challenging ideals, proxies, and organizational practices. Communication Theory 25(1) (2015) 70-90 